\title{
Myocardial Infarction Secondary to Multiple Coronary-Pulmonary Fistula in a High Performance Athlete
}

\author{
Andreina Gil Ramirez ${ }^{1 *}$, Lucrecia M Burgos', Ivan E Chillik', Maria Pelletier', Mariana Larocca \\ Calviño $^{1}$, Pablo Spaletra ${ }^{3}$ and Maria A Elizari ${ }^{4}$
}

${ }^{1}$ Cardiology Service, Instituto Cardiovascular de Buenos Aires, Argentina

${ }^{2}$ Cardiology Staff, Instituto Cardiovascular de Buenos Aires, Argentina

${ }_{3}^{3}$ Interventional Cardiology Department Staff, Instituto Cardiovascular de Buenos Aires, Argentina

${ }^{4}$ Adult Congenital Heart Diseases Section, Instituto Cardiovascular de Buenos Aires, Argentina

*Corresponding author: Andreina Gil Ramirez, Cardiology Service, Instituto Cardiovascular de Buenos Aires (ICBA), Blanco Encalada 1543-(1428). Buenos Aires, Argentina, ORCID iD: 0000-0001-6772-5266

\section{Introduction}

Coronary fistulas (CF), initially described by Krause in 1865, are uncommon anomalies consistent in communication between coronary arteries and any cardiac cavity or vascular structure [1].

The incidence of $\mathrm{CF}$ is $0.002 \%$ of general population, observed in $0.2 \%$ of adult patients undergoing coronary angiography [2]. More frequently of congenital origin, they have also been described related to invasive procedures, chest trauma or post myocardial infarction. In $55 \%$ of cases they are originated from the right coronary artery, in 35\% from left coronary artery and $5 \%$ in both simultaneously. Seventy percent of CF drain into right cavities (low pressure circuits), 15\% into pulmonary artery and just $3 \%$ into left cavities $[2,3]$.

Most patients remain asymptomatic, and the onset of symptoms appearance depends on left-to-right shunt magnitude. In the long term and with diagnosis delay, CF may evolve to myocardial ischemia due to coronary steal, pulmonary hypertension, heart failure and ruptured fistula aneurysm. Therefore, its detection and early treatment in symptomatic patients is essential [3].

We present a case of CF draining in a pulmonary artery with associated myocardial ischemia, with complex intravascular resolution.

\section{Case Report}

A 40-year-old male patient, with no cardiovascular risk factors or relevant clinical history, was referred to our institution for evaluation and treatment. He denied substance abuse or regular medication, and declared to be a high-performance athlete, trail runner of $70 \mathrm{~km}$ a week. At the end of a $27 \mathrm{~km}$ race, he presented an intense retrosternal oppressive pain, without irradiation, associated with dizziness, which disappeared at rest. It was initially interpreted as a muscular cramp and was treated with non-steroidal anti-inflammatory drugs in a local center. 48 hours later, he consulted a local hospital. There were no abnormal findings on first clinical examination. The 12-lead electrocardiogram (EKG) showed $60 \mathrm{bpm}$ with negative T waves in DIII lead, and left ventricular hypertrophy (Figure 1). He presented a Troponin I value of $2.75 \mathrm{ng} / \mathrm{ml}$ (normal value: Less than $0.4 \mathrm{ng} / \mathrm{ml}$ ), and Creatine Kinase of $475 \mathrm{U} / \mathrm{ml}$ (normal value: Less than $180 \mathrm{U} / \mathrm{ml}$ ), rest of metabolic panel was within normal limits. An echocardiogram was performed which showed preserved left ventricular function with no alterations in segmental motility, without valvular disease; and a thoracic angiotomography that excluded aortic syndrome and pulmonary thromboembolism.

In a second visit, a multislice computed coronary tomography (MSCT) was performed and revealed multiple

Citation: Gil Ramirez A, Burgos LM, Chillik IE, Pelletier M, Larocca Calviño M, et al. (2019) Myocardial Infarction Secondary to Multiple Coronary-Pulmonary Fistula in a High Performance Athlete. Int J Clin Cardiol 6:134. doi.org/10.23937/2378-2951/1410134

Accepted: January 12, 2019; Published: January 14, 2019

Copyright: (C) 2019 Gil Ramirez A, et al. This is an open-access article distributed under the terms of the Creative Commons Attribution License, which permits unrestricted use, distribution, and reproduction in any medium, provided the original author and source are credited. 

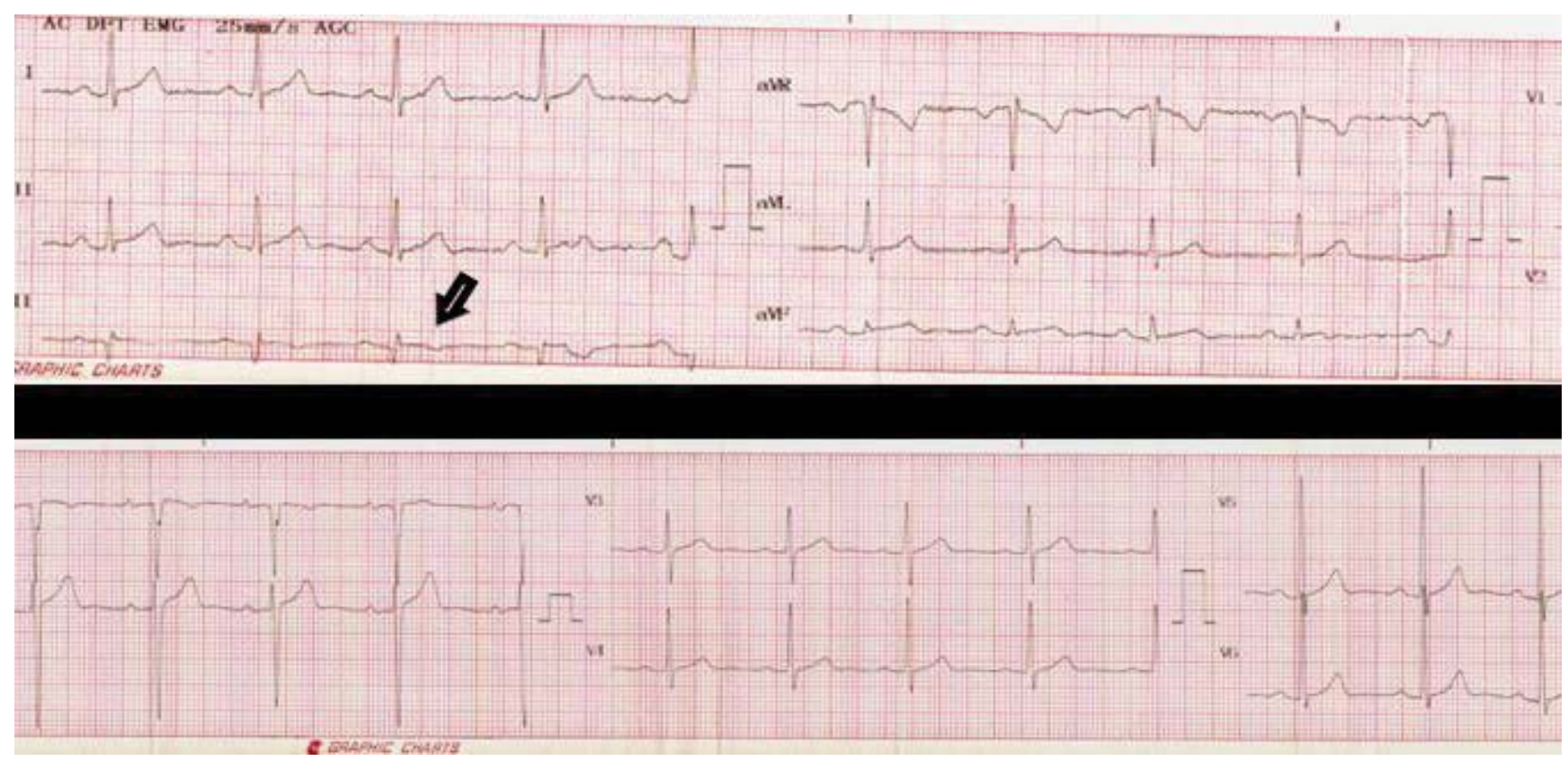

Figure 1: 12-lead electrocardiogram showing left ventricular hypertrophy and negative T waves in lead DIII (black arrow).

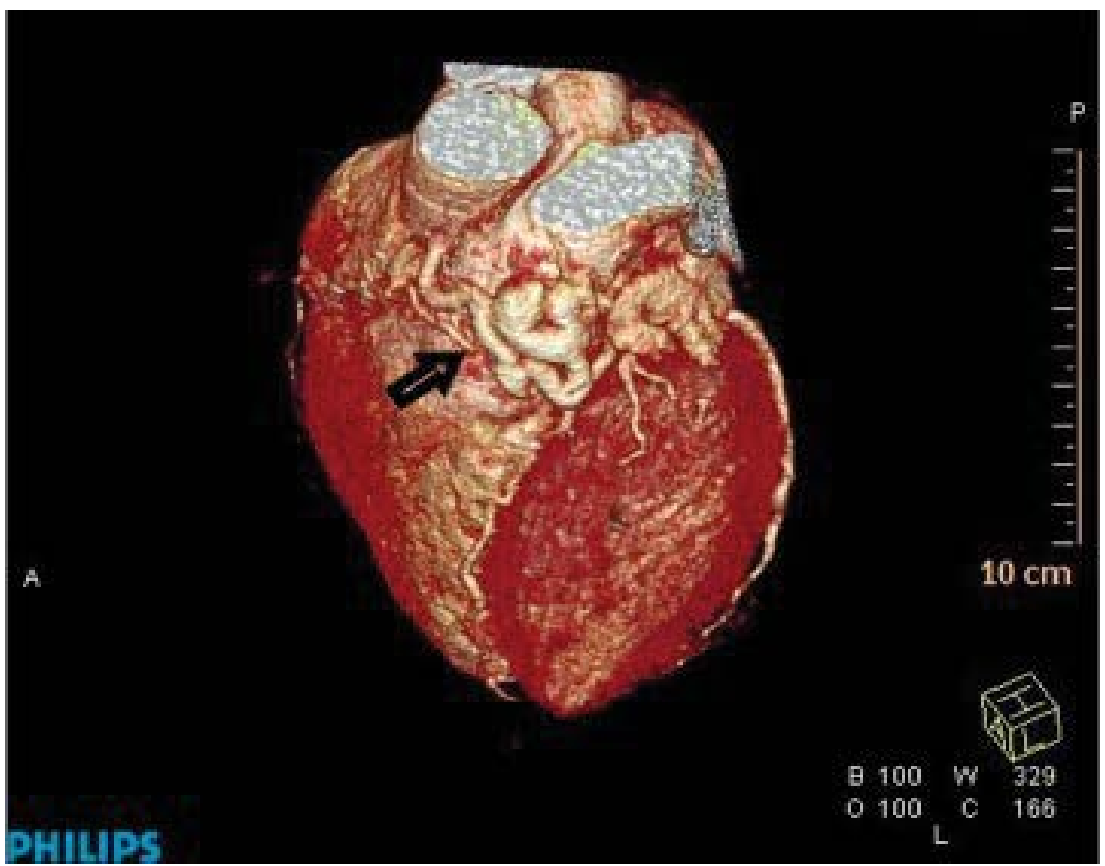

Figure 2: Multislice coronary tomography with 3D reconstruction. Multiple pulmonary coronary fistulas from the septal branch of the anterior descending artery and right coronary artery (black arrow).

pulmonary CF from the septal branch of the left anterior descending artery (LADA) and right coronary artery (RCA) (Figure 2). Suspecting associated myocardial infarction, a cardiac magnetic resonance was requested and showed late gadolinium enhancement in inferoapical segments, with necrotic ischemic pattern and transmural extension (Figure 3). For treatment planning a coronary angiography was performed to evaluate CF morphology, observing a Sakakibara A complex and tortuous macrofistula emerging from the proximal segment of LADA with a common stem and 2 branches of 2 $\mathrm{mm}$ diameter each one, and a Sakakibara A macrofistula of $2 \mathrm{~mm}$ diameter from the proximal segment of RCA, both draining into the pulmonary artery.
From a multidisciplinary approach, given its clinical presentation and morphology of the fistulas, percutaneous treatment was decided. Fistulous tracts were cannulated selectively with Progreat $^{\circledast}$ microcatheter mounted on a BMW 0.014 guide wire and Barricade $^{\circledast}$ coils (Helical SR and Complex SR) were deployed (Figures 4A, Figure 4B, Figure 5A and Figure $5 B$ ), with trivial residual flow. There were no complications during the procedure.

Two months after percutaneous treatment, a follow-up echocardiogram showed a high velocity flow along the origin of the RCA and continuous flow at pulmonary artery level; with a functional test without in- 

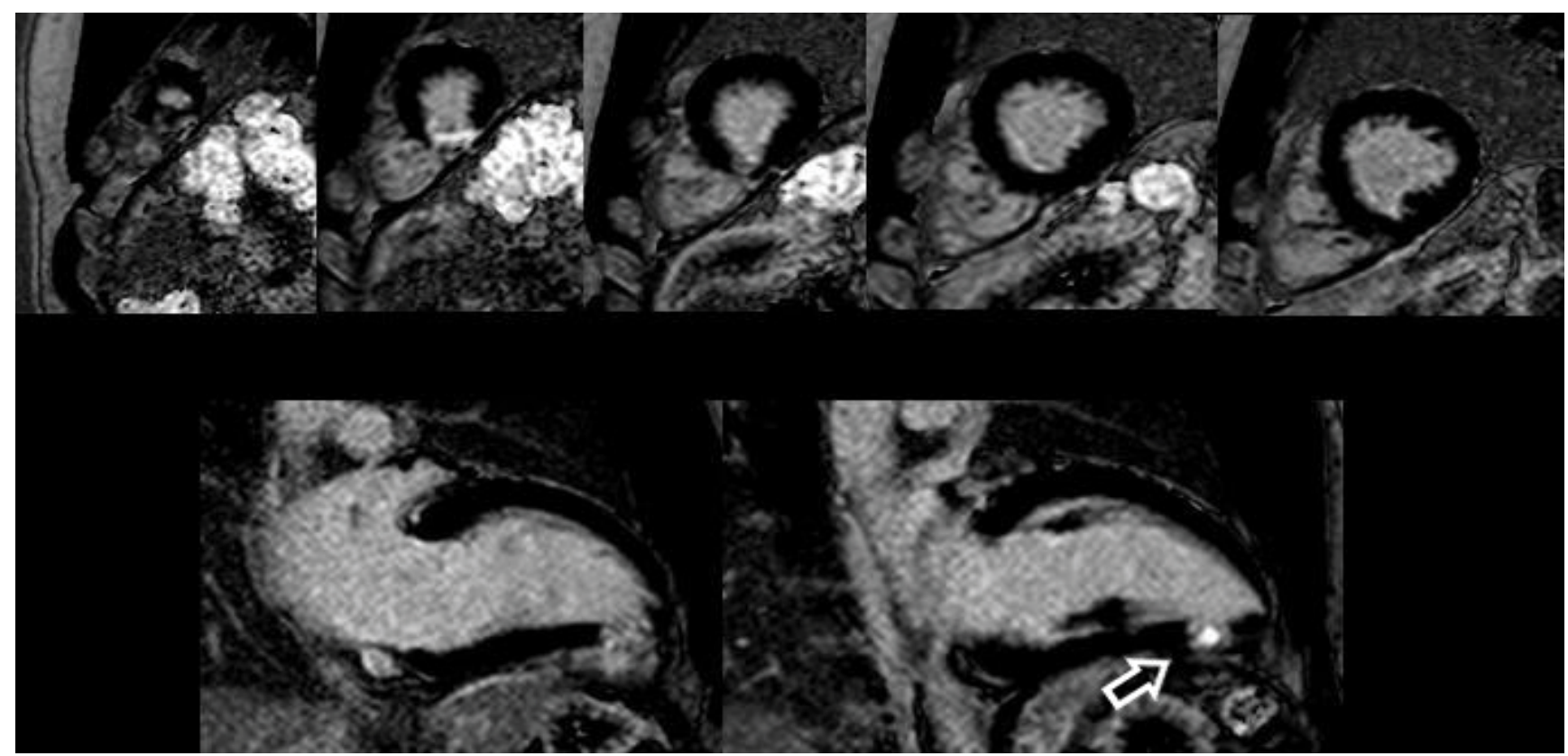

Figure 3: Cardiac magnetic resonance (T1-weighted gradient echo acquisition). Short and long axis views. Late gadolinium enhancement in inferoapical segments, with necrotic ischemic pattern and transmural extension (white arrows).
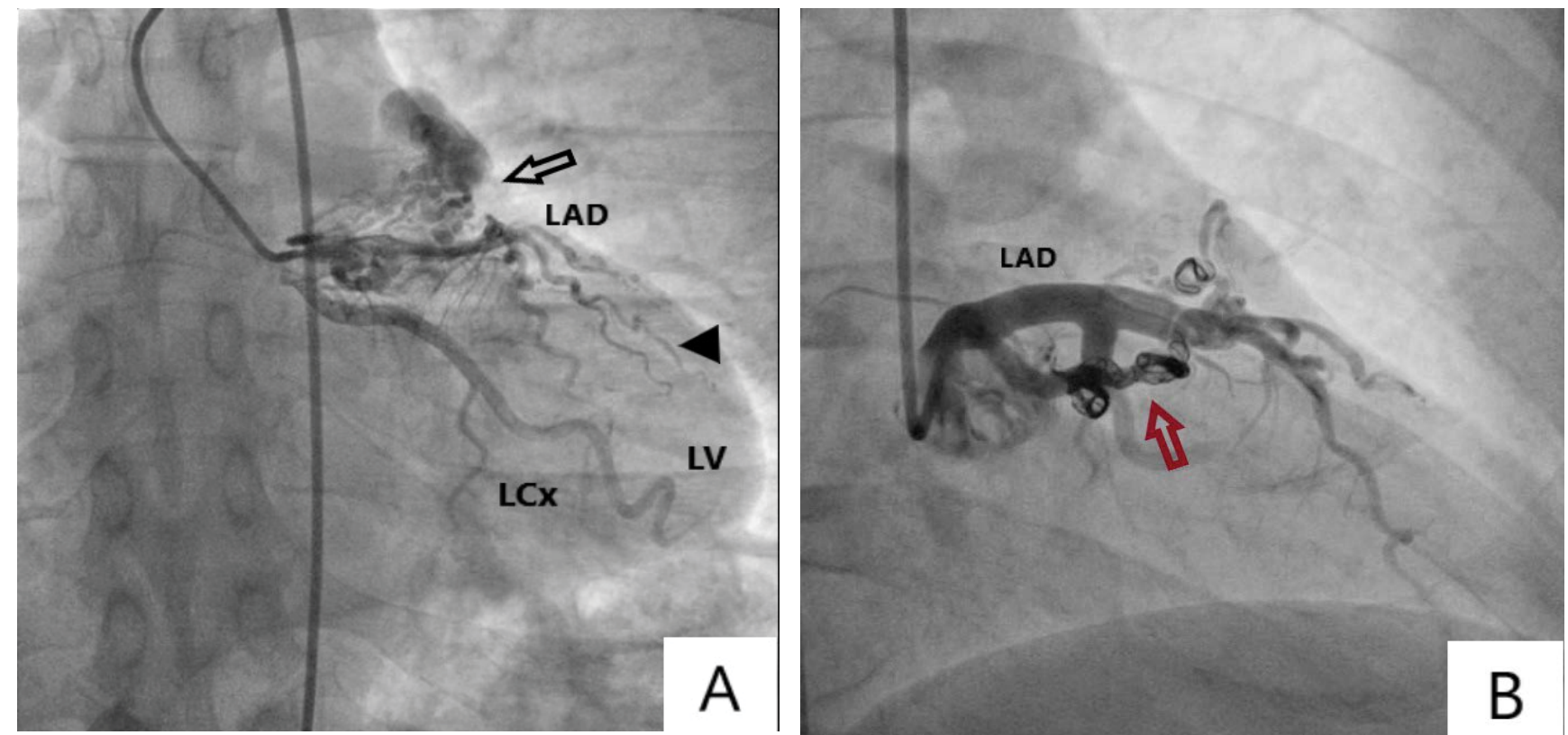

Figure 4: Left coronary artery in a coronary angiography. LAD: left anterior descending artery. LCx: Left circumflex artery. LV: Left ventricle. A) Left anterior oblique projection shows complex fistula coursing superiorly from the proximal third of LAD (black arrow). The distal vessel is underfilled with contrast because of high volume runoff into the fistula (black arrowhead); B) Closed coronary fistula with Barricade ${ }^{\circledR}$ coils with trivial residual flow (red arrow).

duced ischemia and Holter EKG without ventricular arrhythmias. In addition, a MSCT revealed contrast opacification of pulmonary CF embolized with coils, not being able to specify if they were filled from the coronary or the pulmonary artery. Residual permeability of LADA coronary fistula was suspected, but the patient declined a confirmatory coronary angiography.

At discharge, he was treated with clopidogrel 75 $\mathrm{mg}$ and acetylsalicylic acid $100 \mathrm{mg}$. At 12 months he remains asymptomatic, and clopidogrel was stopped due to lack of evidence in long term benefits with this drug. He is performing low impact physical activity within $85 \%$ of target heart rate, with periodical follow up with echocardiogram and Holter EKG. Competitive sport was discouraged. We support the idea to perform a new coronary angiogram in the near future, which is the best method to define CF anatomy and the amount of residual flow.

\section{Discussion}

Pulmonary CF present an uncertain evolution in adult patients, symptoms onset depends on time and fistula size. Angelini, et al. proposed a diagnostic algorithm, in which transthoracic echocardiography and stress 


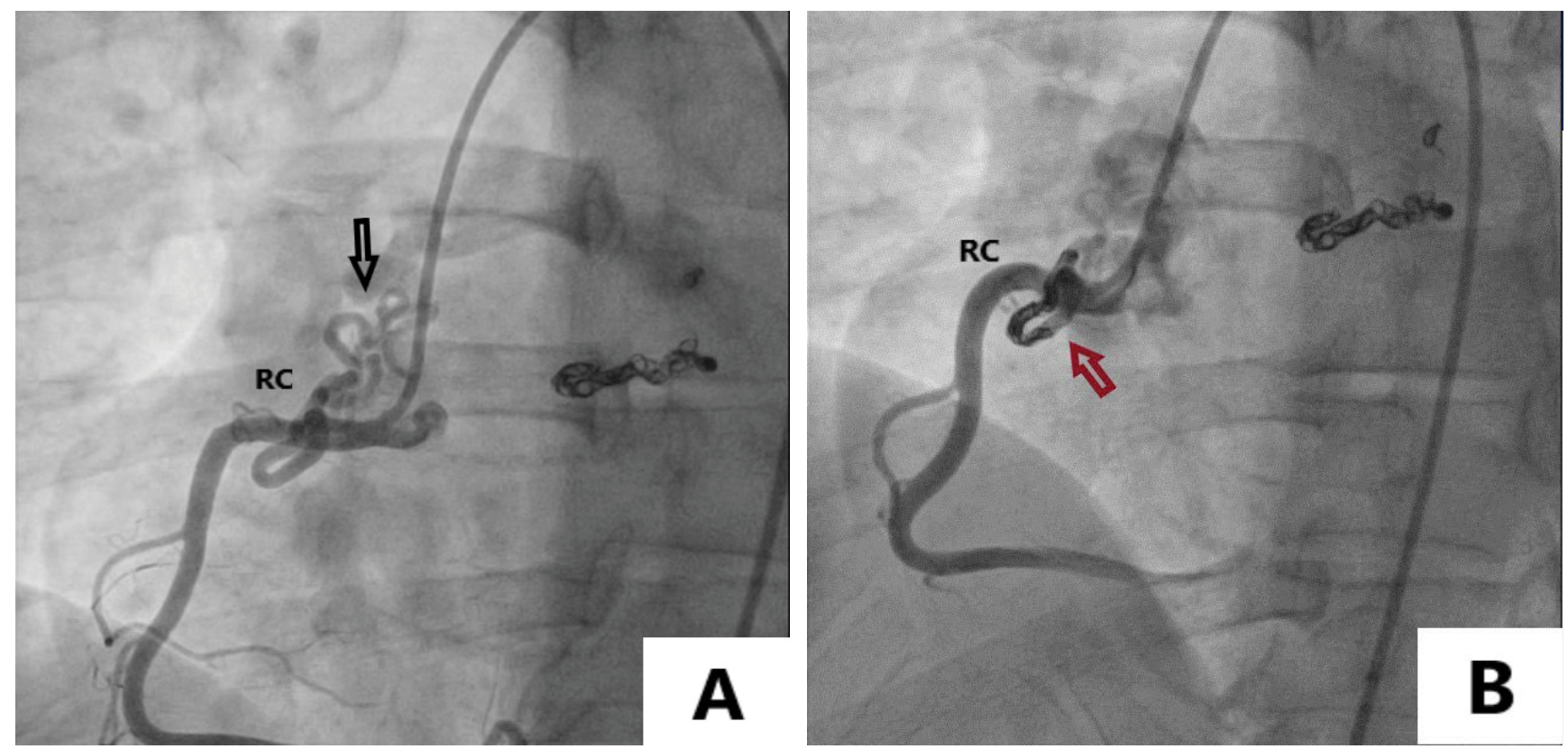

Figure 5: Right coronary artery in coronary angiography. RC: Right coronary artery. A) Pulmonary coronary fistula coursing from the proximal third of RCA (black arrow) B) Closed coronary fistula with Barricade ${ }^{\circledR}$ coils (dotted arrow).

tests play a major role in its detection. However, in patients with severe symptoms and suggestive physical examination and anamnesis, it is recommended to perform coronary angiography as gold standard [4].

Definite closure is indicated in patients with large or complex CF regardless of symptoms. In those with moderate size, treatment should be performed if associated with symptoms, myocardial ischemia, arrhythmias, left ventricular dysfunction or endarteritis [5].

Surgical ligature of CF was initially described by Biorck in 1947, and represents the most effective treatment [6]. Subsequently, percutaneous closure was developed using devices, reducing complications related to conventional surgery, with success rates of $86-90 \%$ in several series $[7,8]$. It is indicated in CF with favorable anatomy (non-tortuous vessels, accessible distal portion and without other associated heart diseases). In complex and proximal fistulas, size is not the most relevant criteria for treatment [9]. Comparing observational cohorts of both techniques, percutaneous closure presents similar success rates and residual fistula (20-30\%) compared to surgical approach [10].

With proper treatment evolution is favorable, although long-term cardiological follow up is recommended to detect recanalization of fistulas, calcification, residual leaks and associated arrhythmias $[5,11]$. According to clinical practice guidelines, it is possible to perform competitive physical activity after treatment in the absence of residual myocardial ischemia and ventricular arrhythmias in stress tests [12].

There is no strong evidence supporting antiagregation after invasive treatment, anticoagulation is suggested in fistulas with aneurysms, associated thrombosis or residual slow flow [10].

\section{Conclusion}

Pulmonary CF are rare anomalies with a broad clinical spectrum. The initial approach in adults is antiagregation and ruling out coronary ischemia. Any complication or symptom justifies aggressive treatment. The traditional one has been surgical, but in the last decades percutaneous treatment constitutes a valid option. The objective is to reduce ischemic risk, arrhythmias and fatal events. However, we recommend individual assessment of each patient to define treatment. This group requires periodic cardiological monitoring to detect new complications in the evolution.

Patient provided his informed consent for the publication of this case report.

\section{Conflict of Interest}

Authors declare no conflict of interest.

\section{References}

1. Krause W (1865) Ueber den Ursprung einer akzessorischen A. coronaria aus der A. pulmonalis Z Ratl Med 24: 225-229.

2. Fernandes ED, Kadivar $H$, Hallman GL, Reul GJ, Ott DA, et al. (1992) Congenital malformations of the coronary arteries: The Texas Heart Institute experience. Ann Thorac Surg 54: 732-740.

3. Schumacher G, Roithmaier A, Lorenz HP, Meisner H, Sauer U, et al. (1997) Congenital coronary artery fistula in infancy and childhood: Diagnostic and therapeutic aspects. Thorac Cardiovasc Surg 45: 287-294.

4. Angelini P (2002) Coronary artery anomalies-current clinical issues: Definitions, classification, incidence, clinical relevance, and treatment guidelines. Tex Heart Inst J 29: 271-278.

5. Warnes CA, Williams RG, Bashore TM, Child JS, Connolly $\mathrm{HM}$, et al. (2008) ACC/AHA 2008 Guidelines for the Management of Adults with Congenital Heart Disease: 
Executive Summary: A report of the American College of Cardiology/American Heart Association Task Force on Practice Guidelines (writing committee to develop guidelines for the management of adults with congenital heart disease). Circulation 118: 2395-2451.

6. Biorck G, Crafoord C (1947) Arteriovenous aneurysm on the pulmonary artery simulating patent ductus arteriosus botalli. Thorax 2: 65-74.

7. Reidy JF, Anjos RT, Qureshi SA, Baker EJ, Tynan MJ (1991) Transcatheter embolization in the treatment of coronary artery fistulas. J Am Coll Cardiol 18: 187-192.

8. Said SA, Nijhuis RL, Op den Akker JW, Kimman GP, Van Howelinguen KG, et al. (2011) Diagnostic and therapeutic approach of congenital solitary coronary artery fistulas in adults: Dutch case series and review of literature. Neth
Heart J 19: 183-191.

9. Reddy G, Davies JE, Holmes DR, Schaff HV, Singh SP, et al. (2015) Coronary Artery Fistulae. Circ Cardiovasc Interv 8.

10. Kiefer TL, Crowley AL, Jaggers J, Harrison JK (2012) Coronary arteriovenous fistulae: The complexity of coronary artery-to-coronary sinus connections. Tex Heart Inst J 39: 218-222.

11. Cheung DL, Au WK, Cheung HH, Chiu CS, Lee WT (2001) Coronary artery fistulas: Long-term results of surgical correction. Ann Thorac Surg 71: 190-195.

12. Peidro R (2013) Recomendaciones para la participación en deportes competitivos en personas con anormalidades cardiovasculares. Sociedad Argentina de Cardiología. Revista Argentina de Cardiología 81: 11-13. 